\title{
Thymic Cord
}

National Cancer Institute

\section{Source}

National Cancer Institute. Thymic Cord. NCI Thesaurus. Code C124590.

A fibrous band that connects the cervical thymus to the pharynx or mediastinum. 